\title{
Is sickle cell anemia a risk factor for severe dental malocclusion?
}

\section{Cyrene Piazera Silva COSTA ${ }^{(a)}$ Halinna Larissa Cruz Correa de CARVALHO(a) \\ Soraia de Fátima Carvalho SOUZA ${ }^{(b)}$ \\ Erika Bárbara Abreu Fonseca THOMAZ(c)}

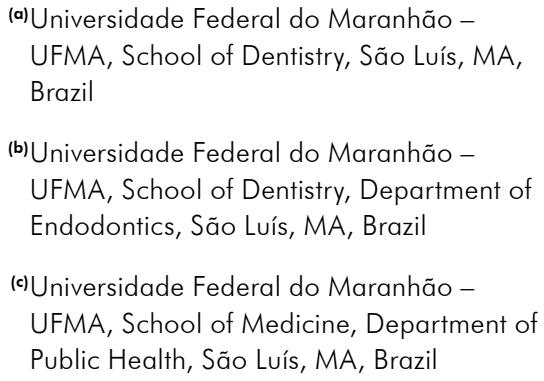

Declaration of Interests: The authors certify that they have no commercial or associative interest that represents a conflict of interest in connection with the manuscript.

Corresponding Author:

Soraia de Fátima Carvalho Souza

E-mail: endosoraia@gmail.com

DOI: 10.1590/1807-3107BOR-2015.vol29.0017

Submitted: Nov 05, 2013

Accepted for publication: Sep 08, 2014

Last revision: Nov 25, 2014
Abstract: The aim of this study was to investigate possible associations between sickle cell anemia (SCA) and the severity of dental malocclusion (MO). This was a retrospective cohort study of 93 individuals with SCA (G1) and 186 individuals without the disease (G2). SCA patients were randomly selected by a simple draw from patients treated in the Centro de Hematologia e Hemoterapia do Maranhão (HEMOMAR) in northeastern Brazil. Patients aged between 16 and 60 were included after being tested for the hemoglobin S gene. G2 consisted of individuals living in the same residence as the patients. The Dental Aesthetic Index (DAI), as well as some morphological deviations not included in DAI, were used for the orthodontic evaluation of MO. Poisson regression with robust variance adjustment was employed to estimate relative risk (RR). In the multivariate analysis, SCA was associated with moderate $(R R=1.36)$ and very severe $\mathrm{MO}(\mathrm{RR}=8.0)$. SCA is correlated with anterior tooth loss $(R R=1.94)$, anterior spacing $(R R=1.66)$, overjet $(R R=1.87)$, anterior crossbite $(R R=1.94)$, and open bite $(R R=1.94)$. Thus, SCA is a risk factor for moderate and very severe MO.

Keywords: Malocclusion; Anemia, Sickle Cell; Epidemiology.

\section{Introduction}

Sickle cell anemia (SCA) is an autosomal recessive nonsex-linked hemoglobinopathy predominant among Afro-descendants. Its cause is a point mutation in the $\beta$-chain of hemoglobin which results in an abnormal hemoglobin variant called hemoglobin S (HbS). ${ }^{1}$ SCA has been categorized as a public health issue as it affects a significant percentage of the world's population. It is considered the most prevalent inherited disease in Brazil; the state of Bahia has the highest incidence of SCA at 15.4 cases per 10,000 live births and Maranhão is in fourth position with 7.1 cases per 10,000 live births. $^{2}$

Because red blood cells need to be constantly produced towing to their short lifespan, SCA patients commonly suffer from hyperplasia and compensatory expansion of the bone marrow, which may result in bone changes even of the craniofacial bone structures. One study reported depression of the nasal bridge, midfacial overgrowth resulting in maxillary protrusion, and the formation of a thick trabecular pattern. ${ }^{3}$ Furthermore, a significantly more pronounced vertical pattern (clockwise) is observed as inferior and total face height angles and posterior rotation of the mandible are increased in SCA. ${ }^{4}$ 
Changes to the craniofacial bone structures are believed to be factors that contribute to the development of dental malocclusion (MO). Moreover, delayed tooth eruption and an unusually high degree of periodontitis are common in SCA, both of which can also result in MO. ${ }^{4}$ Thus, the rationale for an association between this disease and dental MO is plausible. However, the role of SCA in the establishment of MO remains controversial as far as the different types of $\mathrm{MO}$ and the varying degrees of severity are concerned. Most studies on this issue have been performed with small samples, using descriptive, case report, or crosssectional designs, and with no control for confounding factors, on samples that grouped the deciduous and mixed dentitions, and without considering the severity of MO. ${ }^{5}$ Thus, the objective of this study was to assess the possible associations between SCA and the severity of MO. The null hypothesis tested was that there is no difference in the severity of MO between patients with SCA and control subjects.

\section{Methodology}

\section{Design and location of study}

This was a cohort study with both retrospective and prospective phases. The exposure (SCA) and the outcome of interest $(\mathrm{MO})$ were already existent at the time of the study and the allocation of subjects in the study took place from retrospectively investigating for the exposure condition in hospital records. Therefore, the exposure was retrospectively assessed; however, the outcome was prospectively diagnosed. The study was conducted in the Centro de Hematologia e Hemoterapia do Maranhão (HEMOMAR), a state healthcare institution responsible for government policies related to hematology and transfusion medicine in the State of Maranhão, Brazil. Because this is the referral center for the treatment of hematologic diseases, it covers the entire state.

\section{Subjects of study}

\section{SCA Group}

SCA was diagnosed using the electrophoresis technique. The diagnosis of SCA by neonatal screening for the $H b S$ gene was confirmed from the records.
Individuals with SCA, aged between 16 and 60 years old (since the roots of the second molars have fully developed by the age of 16), were randomly selected from the patients' records of HEMOMAR to form the study group (G1). Randomization of G1 was performed by draw.

\section{Control Group}

HEMOMAR performs extended family screening for SCA, as part of a national screening program for congenital diseases. Relatives withoutSCA living with the individuals in G1 were recruited to form a control group (G2). Absence of the disease was confirmed by checking the medical records of the social services department of HEMOMAR. Randomization of G2 was performed by draw.

Exclusion criteria for both groups were history of orthodontic treatment (OT), endocrine-metabolic disorders, mental retardation, genetic craniofacial syndromes and disorders known to have a negative effect on occlusion, and history of head and neck surgery or head and neck radiation, as well as refusal to participate in the study.

\section{Calculated sample size}

Seventy-eight individuals with SCA and 156 without SCA would have $80 \%$ power to identify differences of $20 \%$ in the incidence of $\mathrm{MO}$ between the two groups [Relative Risk $(R R)=1.4$ ] with an alpha error of $5 \%$ estimating a frequency of $50 \%$ of $\mathrm{MO}$ in those without SCA. Finally, 20\% more patients were enrolled in the study to compensate for an expected loss to treatment; thus, giving a total of 279 subjects (93 in G1 and 186 in G2).

\section{Data collection}

Data was collected between January and June 2011. Demographic data of participants were obtained from patients' records in HEMOMAR including name, address, phone number, date of birth, gender, and self-reported race categorized as Black, White, or other according to the criteria of the Instituto Brasileiro de Geografia e Estatística - IBGE. ${ }^{6}$ Information on socioeconomic status according to economic classification criteria in Brazil ${ }^{7}$ was obtained by interviews (categorized as A/B, C, or D/E). 
The Dental Aesthetic Index (DAI) was used to evaluate the severity of $\mathrm{MO}$ and the necessity of OT. Individuals were categorized as: without MO or with mild MO (without the need of treatment), moderate MO (elective treatment), severe $\mathrm{MO}$ (desirable treatment), and very severe $\mathrm{MO}$ (treatment essential). This index is recommended by the World Health Organization and has good reproducibility and validity. Moreover, posterior crossbite, posterior open bite, and overbite, which are not covered by DAI, were also assessed. ${ }^{8}$

The orthodontic clinical examinations were conducted in a dental office by three experienced examiners (minimum Kappa $=0.9$ ) under artificial light using a community periodontal index probe and disposable wooden spatulas. Prior to the evaluation, each subject was submitted to bite deprogramming using plastic strips (Long strips).

\section{Statistical analysis}

Data were analyzed using Stata software version 10 (Stata Corp., College Station, USA). The normality of the sample was tested using the Shapiro-Wilk test. The $95 \%$ confidence intervals (CI) for severity of MO and need for OT were estimated for both groups and compared using the Kruskal-Wallis and Chi-square tests. A level of significance of $5 \%$ was adopted to reject the null hypothesis. The associations between SCA and severity of MO were estimated by separate Poisson regression models with robust adjustments of the variance; the unadjusted and adjusted relative risk (RR) and respective 95\%CI were calculated. Multinomial logistic regression analysis is used when the outcome has more than two categories and odds ratio $(\mathrm{OR})$ is used as an indicator of the prevalence ratio (PR) or RR. However, recent studies indicate that OR can be a biased estimator of PR and RR, often generating overestimated measures of association, and thus leading to spurious interpretations. Hence, the use of log multinomial regression models and Poisson regression with specific robust variance have been proposed. ${ }^{9}$

Additional models were tested considering each of the components of DAI as outcomes, as well as posterior crossbite, posterior open bite, and overbite, which are types of MO that are not included in DAI.
The criterion used for covariables to enter the model as potential confounding factors was a statistical significance of $<20 \%(p<0.20)$ in the univariate analysis. The selection of covariables was by backwards stepwise regression to eliminate variables with $p>0.10$.

\section{Ethical aspects}

The study was approved by the local Research Ethics Committee (protocol \#23115-04993/2010-71). All individuals were invited to participate in the study and signed written consent forms.

\section{Results}

The characteristics of the study participants are shown in Table 1. DAI was higher in G1 than in G2 (Figure). The variables age and DAI had asymmetric distributions in both groups $(p<0.001)$. There were no statistically significant differences between groups with respect to sociodemographic variables; however, the median DAI was higher in G1 than in G2 $(p<0.001)$.

Significant differences between groups were found for ethnicity, gender, and socioeconomic status in relation to $\mathrm{MO}(p<0.05)$. These variables were inserted into the adjusted regression models, as was age.

The frequency of normal occlusion of teeth or mild MO was higher in G2 than in G1, while very severe MO was most commonly observed in G1 $(p<0.001)$, showing that individuals with SCA have a greater need of OT than controls (Table 2).

In the unadjusted analysis, individuals in G1 had a greater risk of developing moderate to very severe MO compared to those in G2. After adjusting for gender, ethnicity, age, and socioeconomic status, significant associations remained for moderate $(\mathrm{RR}=1.36$; 95\%CI: 1.07-1.73) and for very severe MO (RR = 8.0; 95\%CI: 3.21-19.33) (Table 2). Adjusted Poisson models explained $4 \%$ of the variability in moderate $\left(R^{2}=0.04\right) \mathrm{MO}, 15 \%$ of the variability in severe $\mathrm{MO}\left(\mathrm{R}^{2}=0.15\right)$, and $37 \%$ of the variability in very severe $\mathrm{MO}\left(\mathrm{R}^{2}=0.37\right)$.

On evaluating the frequency of each of the DAI components, SCA was associated to an increased prevalence of anterior tooth loss $(\mathrm{RR}=1.94$; 95\% CI: $1.33-2.83)$, anterior spacing $(\mathrm{RR}=1.66$; $95 \% \mathrm{CI}$ : 
Table 1. Sociodemographic characteristics of the participants.

\begin{tabular}{|c|c|c|c|c|c|}
\hline \multirow{2}{*}{ Variables } & \multicolumn{2}{|c|}{ Gl (n = 93) } & \multicolumn{2}{|c|}{$\mathrm{G} 2(\mathrm{n}=186)$} & \multirow{2}{*}{$p$} \\
\hline & $\mathrm{n}$ & $\%(95 \% \mathrm{Cl})$ & $\mathrm{n}$ & $\%(95 \% \mathrm{Cl})$ & \\
\hline Ethnicity & & & & & $0.62^{b}$ \\
\hline White & 3 & $3.2(0.7-9.1)$ & 8 & $4.3(18.7-83.0)$ & \\
\hline Black & 61 & $65.6(55.0-75.1)$ & 111 & $59.7(52.2-67.8)$ & \\
\hline Other & 29 & $31.2(22.0-41.6)$ & 67 & $36.0(29.1-43.4)$ & \\
\hline Gender & & & & & $0.20^{b}$ \\
\hline Female & 47 & $50.5(40.0-61.1)$ & 109 & $58.6(51.2-65.8)$ & \\
\hline Male & 46 & $49.5(38.9-60.0)$ & 77 & $41.4(34.2-48.8)$ & \\
\hline Economic status $^{a}$ & & & & & $0.32^{\mathrm{b}}$ \\
\hline$A-B$ & 23 & 24.7 (16.4-34.8) & 61 & $32.8(26.1-40.0)$ & \\
\hline C & 59 & $63.5(52.8-73.2)$ & 109 & $58.6(51.2-65.8)$ & \\
\hline \multirow[t]{2}{*}{$\mathrm{D}-\mathrm{E}$} & 11 & $11.8(6.0-20.2)$ & 16 & $8.6 ; 5.0-13.6)$ & \\
\hline & & Median (IQD) & & Median (IQD) & \\
\hline Age & & $26.0(10.0)$ & & $26.0(9.0)$ & $0.59 c$ \\
\hline DAl & & $30.0(14.0)$ & & $29.5(7.0)$ & $<0.001^{c}$ \\
\hline
\end{tabular}

SCA: Sickle Cell Anemia; 95\%Cl: 95\% Confidence Interval; IQD: Inter-Quartile Deviation; DAI: Dental Aesthetic Index; ${ }^{\circ}$ Economic status

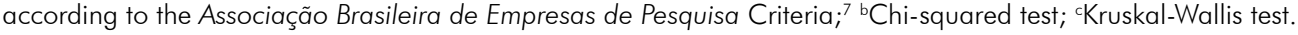

1.29-2.14), overjet ( $\mathrm{RR}=1.87 ; 95 \% \mathrm{CI}: 1.49-2.36)$, anterior crossbite (RR $=1.94 ; 95 \% \mathrm{CI}$ : $1.33-2.83)$, and open bite $(\mathrm{RR}=1.94 ; 95 \% \mathrm{CI}: 1.33-2.83)$. In addition, SCA was associated with a $25 \%$ reduction in the prevalence of irregularities of the maxilla $(\mathrm{RR}=0.75$; $95 \% \mathrm{CI}$ : $0.65-$ 0.86 ) and $12 \%$ of the mandible ( $\mathrm{RR}=0.88$; $95 \% \mathrm{CI}$ : 0.81 0.95). It was not possible to estimate any association between SCA and diastema due to the absence of diastema in control subjects (Table 3).

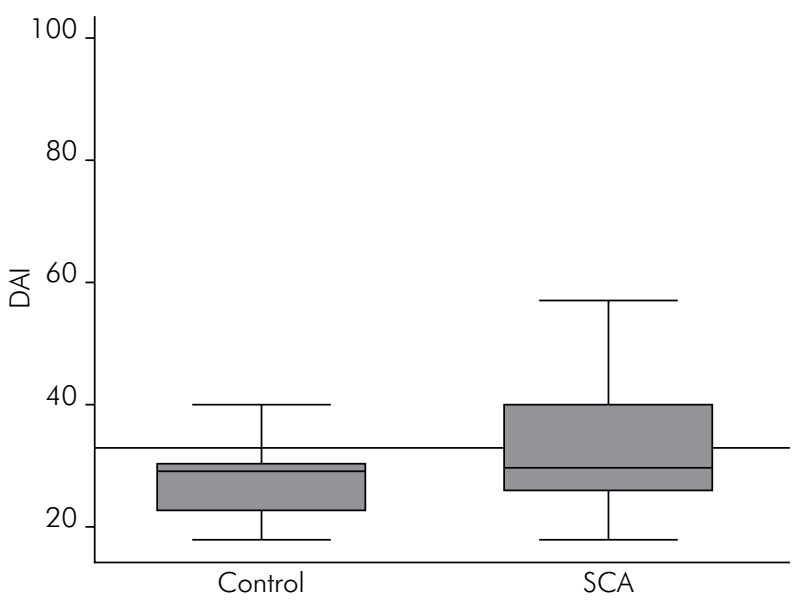

Figure. Box-plot of the dental aesthetic index distribution in sickle cell anemia and control individuals
Associations were not found between SCA and posterior open bite, posterior crossbite, or overbite(Table4).

\section{Discussion}

The null hypothesis of this study was rejected. Significant associations were found between the SCA with moderate $(p=0.01)$ and very severe $(p<0.001)$ $\mathrm{MO}$ in permanent dentition. SCA patients presented a 1.36 times higher risk of developing moderate $\mathrm{MO}$ and 8.0 times higher risk of developing very severe $\mathrm{MO}$ than individuals without the disease. In particular, these associations are because us of the following DAI components: tooth loss, tooth spacing, overjet, anterior crossbite, and anterior open bite. In addition, it was observed that $30.1 \%$ of individuals with SCA had indications for mandatory OT compared to only $2.7 \%$ of the control subjects.

This result confirms the findings of Onyeaso and $\operatorname{Costa}^{10}$ who, on investigating the relationship between dental aesthetics and the need for OT in individuals with SCA in Nigeria, found that 73.3\% of the sample had severe MO with a need of OT. The authors attributed the findings to the degree of craniofacial changes in these individuals. A higher prevalence of overjet and overbite (35\%) was also found among SCA patients when compared with individuals without SCA (15\%) in a small case-control 
Table 2. Severity of dental malocclusion and the need for orthodontic treatment.

\begin{tabular}{lcccccc}
\hline \multirow{2}{*}{ Severity/OT } & \multicolumn{3}{c}{$\mathrm{Gl}$} & & $\mathrm{G} 2$ & \multicolumn{2}{c}{ Unadjusted $^{\text {Adjusted }}$} \\
\cline { 2 - 7 } & $\mathrm{n}$ & $\%(95 \% \mathrm{Cl})$ & $\mathrm{n}$ & $\%(95 \% \mathrm{Cl})$ & $\mathrm{RR}(95 \% \mathrm{Cl})$ & $\mathrm{RR}(95 \% \mathrm{Cl})$ \\
\hline Normal occlusion or mild MO/None & 22 & $23.7(15.4-36.6)$ & 88 & $47.3(39.9-54.7)$ & 1.0 & 1.0 \\
Moderate MO/Optional & 36 & $38.7(28.8-49.4)$ & 72 & $38.7(31.7-46.1)$ & $1.38(1.06-1.80)$ & $1.36(1.07-1.73)$ \\
Severe MO/Highly desirable & 7 & $7.5(3.1-14.9)$ & 21 & $11.3(7.1-16.7)$ & $1.25(0.59-2.66)$ & $1.33(0.76-2.34)$ \\
Very severe MO/Essential & 28 & $30.1(21.0-40.5)$ & 5 & $2.7(0.9-6.2)$ & $10.42(4.27-25.37)$ & $8.0(3.21-19.33)$ \\
\hline
\end{tabular}

MO: Dental Malocclusion; OT: Orthodontic Treatment; DAI: Dental Aesthetic Index; 95\%Cl: 95\% Confidence Interval; RR: Risk Relative;

${ }^{\circ}$ Adjusted for self-reported ethnicity, gender, age, and socioeconomic status.

Table 3. Dental malocclusion in anterior segments according to the components of the Dental Aesthetic Index in sickle cell anemia patients and control subjects (northeastern Brazil, 2011).

\begin{tabular}{|c|c|c|c|c|c|c|c|}
\hline & \multicolumn{2}{|c|}{ G1 } & \multicolumn{2}{|c|}{ G2 } & \multirow{2}{*}{$p$} & \multirow{2}{*}{$\begin{array}{l}\text { Unadjusted } \\
\text { RR }(95 \% \mathrm{Cl})\end{array}$} & \multirow{2}{*}{$\begin{array}{c}\text { Adjustedc } \\
\text { RR }(95 \% \mathrm{Cl})\end{array}$} \\
\hline & $\mathrm{n}$ & $\%$ & $\mathrm{n}$ & $\%$ & & & \\
\hline Absence of teeth & & & & & $0.43^{a}$ & & \\
\hline Yes & 39 & 41.9 & 69 & 37.1 & & $1.13(0.83-1.53)$ & $1.94(1.33-2.83)$ \\
\hline No & 54 & 58.1 & 117 & 62.9 & & 1.0 & 1.0 \\
\hline Crowding & & & & & $0.37^{a}$ & & \\
\hline Yes & 74 & 79.6 & 139 & 74.7 & & $1.06(0.93-1.26)$ & $1.06(0.93-1.21)$ \\
\hline No & 19 & 20.4 & 47 & 25.3 & & 1.0 & 1.0 \\
\hline Spacing & & & & & $<0.00^{1 a}$ & & \\
\hline Yes & 56 & 60.2 & 67 & 36.0 & & $1.67(1.30-2.15)$ & $1.66(1.29-2.14)$ \\
\hline No & 37 & 39.8 & 119 & 64.0 & & 1.0 & 1.0 \\
\hline Incisor diastema & & & & & $<0.00^{1 a}$ & & \\
\hline Yes & 14 & 15.0 & 0 & 0.0 & & & \\
\hline No & 79 & 85 & 186 & 100.0 & & & \\
\hline Irregularity of the maxilla & & & & & $<0.00^{1 a}$ & & \\
\hline Yes & 64 & 68.8 & 173 & 93.0 & & $0.74(0.64-0.85)$ & $0.75(0.65-0.86)$ \\
\hline No & 29 & 31.2 & 13 & 7.0 & & 1.0 & 1.0 \\
\hline Irregularity in mandible & & & & & $<0.00^{1 a}$ & & \\
\hline Yes & 80 & 86.0 & 184 & 98.9 & & $0.87(0.80-0.94)$ & $0.88(0.81-0.95)$ \\
\hline No & 13 & 14.0 & 2 & 1.1 & & 1.0 & 1.0 \\
\hline Overiet & & & & & $<0.00^{1 a}$ & & \\
\hline Yes & 63 & 67.7 & 67 & 36.0 & & $1.88(1.48-2.38)$ & $1.87(1.49-2.36)$ \\
\hline No & 30 & 32.3 & 119 & 64.0 & & 1.0 & 1.0 \\
\hline Anterior crossbite & & & & & $0.002^{a}$ & & \\
\hline Yes & 12 & 12.9 & 6 & 3.2 & & $4(1.55-10.34)$ & $3.9(1.51-10.10)$ \\
\hline No & 81 & 87.1 & 180 & 96.8 & & 1.0 & 1.0 \\
\hline Open bite & & & & & $<0.00^{1 a}$ & & \\
\hline Yes & 12 & 12.9 & 1 & 0.5 & & $24(3.16-182.44)$ & $18.46(2.5-136.45)$ \\
\hline No & 81 & 87.1 & 185 & 99.5 & & 1.0 & 1.0 \\
\hline Molar relationship & & & & & $0.10^{\mathrm{b}}$ & & \\
\hline Normal & 4 & 4.3 & 12 & 6.4 & & 1.0 & 1.0 \\
\hline Half cusped altered & 81 & 87.1 & 167 & 89.8 & & $1.02(0.96-1.09)$ & $1.03(0.96-1.09)$ \\
\hline One cusped altered & 8 & 8.6 & 7 & 3.8 & & $1.81(0.88-3.73)$ & $1.57(0.78-3.16)$ \\
\hline
\end{tabular}

RR: Relative Risk; 95\%Cl: 95\% Confidence Interval; ${ }^{\circ} \mathrm{Chi}$-squared test; ${ }^{b} \mathrm{Kruskal}-$ Wallis test; ' ${ }^{\circ}$ djusted for age, gender, ethnicity, and socioeconomic status; dPearson chi-squared test with robust variance. 
Table 4. Malocclusion in the posterior segments (components not included in the DAl) between sickle cell anemia patients and control subjects (northeastern Brazil, 2011 ).

\begin{tabular}{|c|c|c|c|c|c|c|c|}
\hline & \multicolumn{2}{|c|}{ G1 } & \multicolumn{2}{|c|}{ G2 } & \multirow{2}{*}{$P a$} & \multirow{2}{*}{$\begin{array}{l}\text { Unadjusted } \\
\text { RR }(95 \% \mathrm{Cl})\end{array}$} & \multirow{2}{*}{$\begin{array}{c}\text { Adjusted }{ }^{\mathrm{b}} \\
\text { RR }(95 \% \mathrm{Cl})\end{array}$} \\
\hline & $\mathrm{n}$ & $\%$ & $\mathrm{n}$ & $\%$ & & & \\
\hline Posterior open bite & & & & & 0.72 & & \\
\hline Yes & 28 & 30.1 & 60 & 32.3 & & $0.93(0.64-1.36)$ & $0.99(0.69-1.42)$ \\
\hline No & 65 & 69.9 & 126 & 67.7 & & 1.0 & 1.0 \\
\hline Posterior crossbite & & & & & 0.21 & & \\
\hline Yes & 10 & 10.8 & 12 & 6.5 & & $1.67(0.75-3.72)$ & $1.78(0.82-3.86)$ \\
\hline No & 83 & 89.2 & 174 & 93.5 & & 1.0 & 1.0 \\
\hline Overbite & & & & & 0.06 & & \\
\hline Yes & 24 & 25.8 & 30 & 16.1 & & $1.60(0.99-2.57)$ & $1.54(0.97-2.46)$ \\
\hline No & 69 & 74.2 & 156 & 83.9 & & 1.0 & 1.0 \\
\hline
\end{tabular}

RR: Relative Risk; $95 \% \mathrm{Cl}$ : 95\% Confidence Interval; ${ }^{a}$ Chi-squared test; ${ }^{b}$ Adjusted for age, gender, ethnicity, and socioeconomic status.

study comprised 37 cases and 24 controls in Nigeria. ${ }^{11}$ Furthermore, Class II MO was found in 21\% of SCA subjects compared to $2 \%$ of controls $(p<0.05)$ in a cross-sectional study also in Nigeria. ${ }^{12}$

In the present study, associations were found between SCA and higher frequencies of tooth loss $(\mathrm{RR}=1.94)$, spacing in the incisor segments $(\mathrm{RR}=1.66)$, anterior open bite $(R R=1.94)$, overjet $(R R=1.87)$, and anterior crossbite $(R R=1.94)$. Although some of these findings do not have precedents in the literature, they are in agreement with other studies that suggest an association between SCA and MO is plausible. Brown and Sebes ${ }^{13}$ and Alves et al. ${ }^{14}$ reported that the increased number of MO in patients with SCA may be related to muscle imbalance, lack of lip seal or changes in the bone base, and configurations in SCA patients. However, these investigations did not report on the extent of the associations, nor did they adjust for potential confounding factors using multiple regression analyses. Moreover, some studies did not use a control group and thus were only descriptive, ${ }^{13}$ or included different age groups ${ }^{10,12}$ and small sample sizes, ${ }^{11,13}$ and one was a case report. ${ }^{15}$

There are records that frequent vaso-occlusive crises cause ischemic necrosis in individuals with SCA. .14 This process can also affect the maxillomandibular blood supply, which may explain the increased tooth loss and spacing of teeth such as was observed in this study. Overjet has been highlighted in previous studies as one of the most common MO in individuals with SCA. ${ }^{10,16}$ Taylor et al. ${ }^{16}$ and Costa et al. ${ }^{17}$ reported a prevalence of overjet of $48.2 \%$ and $56 \%$, respectively, in individuals with SCA. The results of the current study are similar, with a high prevalence of overjet $(67.7 \%)$, one of the most common MO. However, paradoxically, an association between SCA and anterior crossbite was also found. Most studies point to overjet and not anterior crossbite as a possible consequence of SCA. ${ }^{14,16,17}$ One possible explanation is given by Williams et al. ${ }^{18}$ who suggested that SCA may be associated with increased bone marrow activity and dysplastic maxillary growth.

This study found a prevalence of $79.6 \%$ of crowding and $60.2 \%$ of spacing between incisor segments in G1 (Table 3), thus differing from that of Costa et al. ${ }^{17}$ who found a prevalence of $49 \%$ for crowding and 30.8\% for spacing in the anterior segments of the upper and lower arches. These differences may partly be explained by differences in the age groups of the populations studied, as the current study enrolled an older population (16-60 years) than that in the study by Costa et al. ${ }^{17}$ (10-45 years), as well as by differences in the power of the sample as the authors did not specify the parameters employed to enroll the 140 subjects that formed their sample.

One limitation of the current study is that the sample size was very small to evaluate differences in the frequency of diastema (not observed in G2). However, the sample size estimates were calculated for an alpha error of $5 \%$ and a beta error of $20 \%$, which is conventionally considered to be acceptable. Moreover, the sample size was adequate for the main outcome 
of the study, namely $\mathrm{MO}$ as classified according to DAI. Studies with retrospective designs are limited in respect to the data that can be collected. The high range of ages can introduce some bias, as age is also associated to tooth loss. However, to control this, all associations for that variable were adjusted.

The strengths of the study include the longitudinal design, which is one of the best types to test etiological hypotheses, selection of G1 by random sampling in a state referral service, and the choice of G2 from the same community to reduce possible selection bias. Furthermore, the objective criterion to define SCA based on blood tests at birth, as well as the diagnosis of $\mathrm{MO}$, according to the international gold standard with

\section{References}

1. Fonseca M, Ouies HS, Casamassimo PS. Sickle cell anemia: a review for the pediatric dentist. Pediatr Dent. 2007 MarApr;29(2):159-69.

2. Fry PH. The significance of sickle cell anemia within the context of the Brazilian government's 'racial policies' (1995-2004). Hist Cienc Saude Manguinhos. 2005 May-Aug;12(2):347-70. [Portuguese].

3. Javed F, Correa FO, Nooh N, Almas K, Romanos GE, AlHezaimi K. Orofacial manifestations in patients with sickle cell disease. Am J Med Sci. 2013 Mar;345(3):234-7.

4. Licciardello V, Bertuna G, Samperi P. Craniofacial morphology in patients with sickle cell disease: a cephalometric analysis. Eur J Orthodont. 2007 Jun;29(3):238-42.

5. Costa CPS, Carvalho HLCC, Thomaz EBAF, Souza SFC. Craniofacial bone abnormalities and malocclusion in individuals with sickle cell anemia: a critical review of the literature. Rev Bras Hematol Hemoter. 2012;34(1):60-3.

6. Brasil. Instituto Brasileiro de Geografia e Estatística. Censo 2010. [Internet]. [cited 2012 Mar 18]. Available from: http://www.censo2010.ibge.gov.br/resultados_do_censo2010.php.

7. Associação Brasileira de Empresas de Pesquisa - ABEP. Critério de Classificação Econômica Brasil. [Internet]. 2012. [cited 2012 Feb 8]. Available from: http://www.abep.org/ novo/Content.aspx?SectionID $=84$.

8. Cardoso CF, Drummond AF, Lages EM, Pretti H, Ferreira EF, Abreu MHNG. The Dental Aesthetic Index and dental health component of the Index of Orthodontic Treatment Need as tools in epidemiological studies. Int J Environ Res Public Health. 2011 Aug;8(8):3277-86. assessments carried out by experienced examiners, are methodological safeguards that minimize potential measurement biases.

\section{Conclusions}

SCA appears to be a risk factor for moderate and very severe $\mathrm{MO}$, especially when related to anterior tooth loss, anterior spacing, overjet, anterior crossbite, and open bite.

\section{Acknowledgements}

The authors thank the FAPEMA (Fundação de Amparo à Pesquisa e ao Desenvolvimento Científico e Tecnológico do Maranhão) for grants.

9. Blizzard L, Hosmer DW. The log multinomial regression model for nominal outcomes with more than two attributes. Biom J. 2007 Dec;49(6):889-902.

10. Onyeaso CO, Costa OO. Dental aesthetics assessed against orthodontic treatment complexity and need in Nigerian patients with sickle-cell anemia. Spec Care Dentist. 2009 Nov-Dec;29(6):249-53.

11. Okafor LA, Nonnoo DC, Ojehanon PI, Aikhionbare O. Oral and dental complications of sickle cell disease in Nigerians. Angiology. 1986 Sep;37(9):672-5

12. Oredugba FA, Savage KO. Anthropometric finding in Nigerian children with sickle cell disease. Pediatr Dent. 2002 Jul-Aug;24(4):321-25.

13. Brown DL, Sebes JI. Sickle cell gnathopathy: radiologic assessment. Oral Surg Oral Med Oral Pathol. 1986 Jun;61(6):653-6.

14. Alves PVM, Alves DKM, Souza MMG, Torres SR. Orthodontic treatment of patients with sickle-cell anemia. Angle Orthod. 2006 Mar;76(2):269-73.

15. Pithon MM. Orthodontic treatment in a patient with sickle cell anemia. Am J Orthod Dentofacial Orthop. 2011 Nov;140(5):713-9.

16. Taylor LB, Nowak AJ, Giller RH, Casamassimo PS. Sickle cell anemia: a review of the dental concerns and a retrospective study of dental bone changes. Spec Care Dentist. 1995 JanFeb;15(1):38-42.

17. Costa OO, Kehinde MO, Ibidapo MO. Occlusal features of sickle cell anaemia patients in Lagos, Nigeria. Niger Postgrad Med J. 2005 Jun;12(2):121-4.

18. Williams AO, Lagundoye SB, Johnson CL. Lamellation of the diploe in the skulls of patients with sickle cell anemia. Arch Dis Child. 1975 Dec;50(12):948-52. 